\title{
UNIVERSITY COLLEGE OF NORTH STAFFORDSHIRE NEW PHYSICS LABORATORIES
}

$S^{\mathrm{T}}$ TAGES I and II of the new permanent building for the Physies Laboratories of the University College of North Staffordshire were formally opened on November 6, 1953, by Sir John Cockeroft, director of the Atomic Energy Research Establishment, Harwell. Sir John referred to the importance of the founding of the new University College at Keele, where all students are required to attend courses in the humanities, social studies and experimental sciences during their first year in residence, in contrast to the increasing specialization in most other universities and in some sixth forms in schools. Men of affairs often say that the evils of the world to-day are largely due to science, and that the remedy would be the broader education of scientists. They conveniently forget that the decisions as to how to use the great power of science are generally taken by men brought up on the tradition of humanities. So, while it is important that the scientist shall understand and enjoy the history, tradition and culture of the world we live in, it is equally important that the humanist shall understand the great power and importance of science both for good and evil. Those who think that employers in industry and the Government service want to recruit narrow specialists are misinformed. For, although in the first ten years of employment a scientist or engineer must go deeply into his specialist task, more and more as he grows older he will be forced to take an interest in wider matters, to collaborate with other groups of scientists, to realize that human relations are as important in industry and research establishments as technical and scientific achievement, to express himself clearly and convineingly at meetings and conferences, and to be able to understand scientists from other countries. Finally, in maturity or as old age creeps upon one, one finds oneself one week discussing how to accelerate particles to $25,000 \mathrm{MeV}$. or listening to delegates from twelve different countries working out the problems of European collaboration in nuclear science.

Sir John told the students present how fortunate they were to have the opportunity of delving deeply into physics after their first ('foundation') year, since physics is still the most fascinating of the sciences. Towards the close of the nineteenth century, it was commonly thought that the twilight of the grand period of the development of classical physics was approaching; but suddenly the discovery of radioactivity and the electron, and the rise of the quantum theory transformed the world of physics. Within a few years, the Rutherford-Bohr model of the atom was accepted, followed by the development of nuclear physies from 1919. Since 1946 there have been equally important and exciting developments. Sir John outlined some of these developments in nuclear and other branches of physics. $\mathrm{H}_{\theta}$ was particularly pleased to know that the programme of nesearch in the new laboratories include some branches of solidstate physics, a subject in which there have been remarkable developments during the past decade or so, likely to lead to far-reaching practical applications.

The initial plans for the new building, including details of furniture and fittings, were completed in
August 1950 by Prof. F. A. Vick. The first stage was commenced in March 1951 and occupied in June 1952 ; the second started in April 1952, and the main building work completed in May 1953. The whole building is of 'Orlit' (prefabricated concrete) construction and was erected by Cooper Bros, and John Clayton, Ltd., of Macelesfield, under the supervision of J. R. Piggott (City architect of Stoke-onTrent and honorary architect to the College) and J. A. Pickavance (College architect), on a site adjacent to other science buildings on the 200-acre estate belonging to the College. All the laboratories in the building are on one floor for ease of movement of apparatus and equipment, and there is a special equipment entrance with an I-beam and block and tackle.

Stages I and II are built on an H-plan, the main blocks lying east-west and the linking section northsouth. The north block is designed primarily for research. One large research laboratory has been in use since the summer of 1952. The services, including gas, boosted gas, compressed air, oxygen (for glassblowing, ete.), hot and cold water and circulating water for pumps, etc., and the various electrical supplies are carried on the walls and along a central duct in the floor. The room is divided longitudinally into two by a rack alongside the central duct carrying services connected to the supplies in the duct. Between the rack and one wall is a clear space for pumping frames, furnaces and other experimental equipment. On the other side of the service rack there are long benches in movable sections for electrical measurements, etc., and bookshelves perpendicular to the walls between the windows divide the space into 'cubicles' in each of which two research workers have their desks and places for their books, papers, etc. Thus the advantage of a large research laboratory and small separate rooms are, to some extent, combined, and the arrangement is working well. Opening off the main research laboratory is a room specially equipped for the construction of the electrode systems, etc., of special valves, massspectrographs, discharge tubes and other vacuum devices used for research. There are also two small service rooms, one equipped with a fume cupboard for spraying cathodes, etc., and a large sink for washing glassware, and the other containing the air compressor, gas booster, oxygen cylinders and reducing valves and other ancillaries.

Near the research laboratory is a small workshop, used partly by postgraduate workers and staff for the construction of equipment needed for research and partly for teaching students the elements of workshop practice. This enables the main workshop, outside the building, to be reserved for precision work. The other large laboratory in the north block is used temporarily as a lecture theatre, with an adjacent room, intended eventually as a research laboratory, equipped for the present as a preparation room and apparatus store for the theatre. In this block there is also the main photographic dark-room, a switch room and stores, and staff rooms.

In the linking section of the H-plan is the small battery room, a room for assistant staff and cloakrooms. The battery room contains an accumulator wired to terminals in the various laboratories giving 0-4-16-24 volts, so that eny voltage up to 24 in 


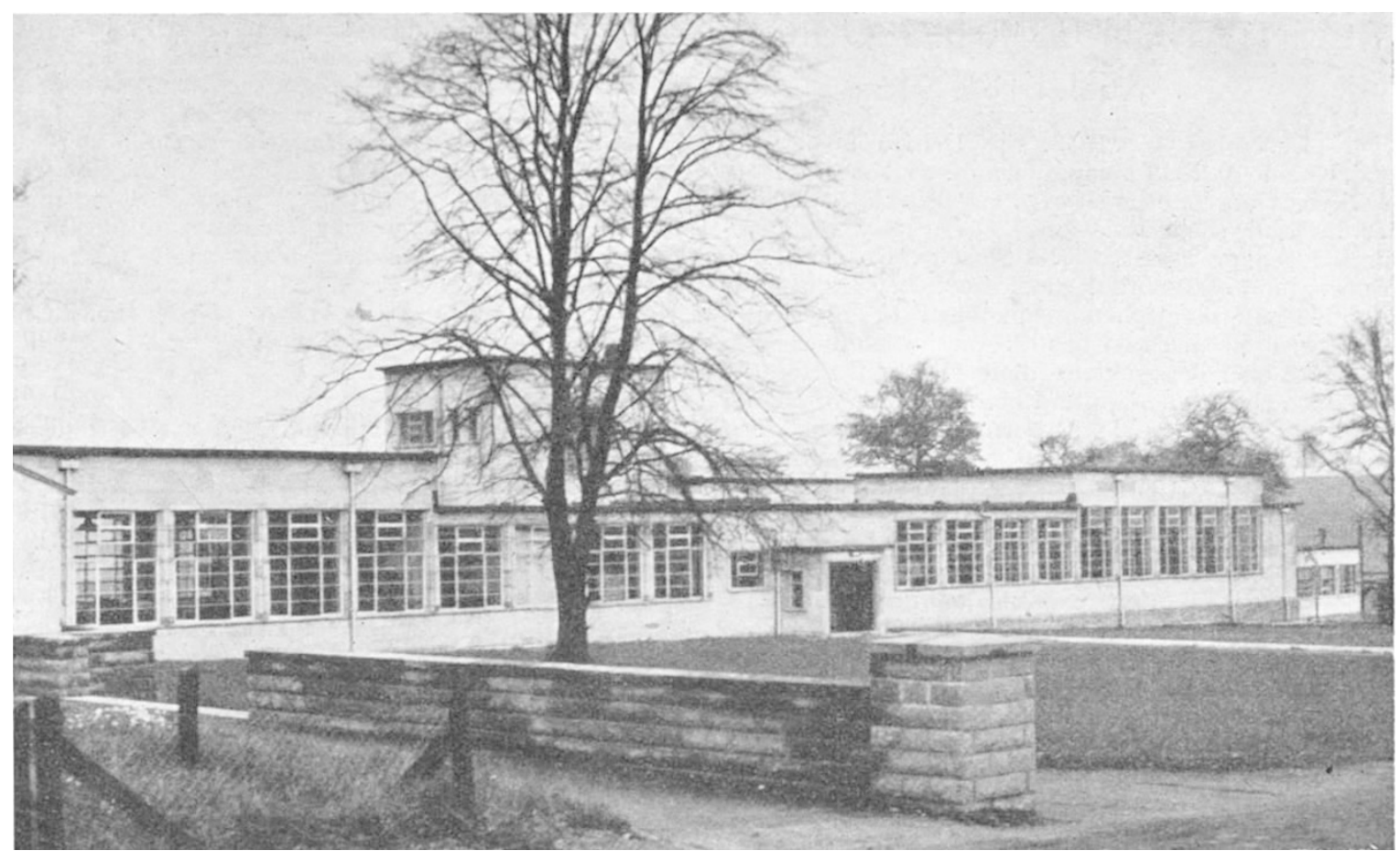

South front of Stage II of the Physics Laboratories. The temporary porch is designed to form part of the corridor when Stage III is built

steps of 4 may be obtained without switches or the plug boards which used to be so familiar in laboratories built twenty-five or more years ago. The other electrical supplies available in the various laboratories are $0-50-100$ volts d.c. from a mercury -arc rectifier, useful for arcs, magnets, etc., and the normal singleand three-phase a.c. supplies. In some laboratories there is a 12-volt a.c. supply from local transformers. All the electrical and other supplies are colour-coded throughout the building; and each electrical supply has its distinctive socket outlet or terminals. The battery room is equipped for accumulator charging.

The south block contains two large teaching laboratories, each with a central service rack as in the research laboratory. Except for two wall benches containing sinks, the apparatus is set out on loose tables, $8 \mathrm{ft}$. $\times 4 \mathrm{ft}$. or $4 \mathrm{ft}$. $\times 4 \mathrm{ft}$., which can be placed near the service racks as required. This gives the maximum flexibility consistent with availability of services. In each laboratory there is also a bench with a concrete top (covered with ground and polished terazzo) on brick pillars for apparatus needing stability. Galvanometer shelves are fixed to the vertical pillars at intervals along the walls, and on brick pillars near the service racks.

Also in the south block is an optics laboratory, equipped with concrete benches as already described, a long photometer bench, and lighting the brightness of which can be varied by a 'Variac'. The window is fitted with an efficient dark blind which can be raised to admit daylight and air when required. When the blind is down, fans can be used to ensure reasonable ventilation. Adjoining the opties laboratory is a photographic dark-room. There are also two smaller laboratories used for advanced work, in which space has been left for a screened room and a small anechoic room for acoustic experiments, and a measurement room containing the standard instruments reserved for calibration of others. This room is also used for colloquia, tutorials, etc. There are the usual staff rooms. A hall in the centre of the block is being fitted with cupboards and display cases for demonstrations in connexion with the various courses and to serve as a small museum. All the laboratories in both wings are fitted with plastic venetian blinds, which have been found most valuable for controlling the light intensity during the summer.

The teaching laboratories so far built are designed to hold twenty-five students in each of three honours years. The elementary laboratory, the main lecture theatres and cloakrooms, etc., are planned as Stage III of the building, to be erected to the south of the present building when licences and money permit. The total floor area of the present building is about 12,000 sq. ft.

Adjacent to the building is the well-equipped precision workshop which serves not only the Physics Department but also the other science departments of the College. It is at present housed in two ex-army huts ; but a more permanent building for it is planned.

Research in progress in the Department is mainly on various branches of electron physics, with special reference to the solid state, including thermionic and field emission, certain properties of semi-conductors and insulators, and the initiation of gas discharges. These topies are not only important in modern physics, but also of great interest to various branches of industry. Moreover, they lend themselves to the training of postgraduate students in methods of reserrch, without requiring special buildings or expensive equipment. Already friendly relations have developed between the Department and some firms, research associations, and Government departments. The British Electricity Authority and the Midlands Electricity Board have helped the Department by generous joint gift of 5,000 guineas, and several firms have contributed by the loan or gift of equipment.
F. A. VICK 